\title{
Modernization of an Aircraft Maintenance Curriculum: Measuring up to the TAC of ABET
}

\author{
Aaron R. Cowin, Terrence K. Kelly \\ Parks College of Engineering and Aviation \\ Saint Louis University
}

\begin{abstract}
The Department of Aerospace Technology at Parks College of Engineering and Aviation, Saint Louis University has offered a Bachelor of Science Degree in Aeronautics with a concentration in Aircraft Maintenance Engineering since 1949. ${ }^{1,2}$ The degree was developed in an era when aircraft manufacturing was in its infancy and aircraft service and repair procedures were almost nonexistent. The curriculum was designed to provide students practical instruction in aircraft manufacturing and repair techniques as well as the mathematical and classic science instruction of the then current contemporary engineering programs. By today's standards, the curriculum parallels that of an engineering technology program.

Over the years, as ABET accredited technology programs continued to submit themselves to rigorous peer review, accreditation evaluations and work toward raising academic standards, the faculty of the Department of Aerospace Technology resisted change and became comfortable in their niche. Much of the resistance to TAC/ABET stems from fear that the word "technology" as part of the degree name will draw an association with a program that graduates technicians and "glorified mechanics". This antiquated philosophy and refusal to deviate from the traditional model has resulted in a department that has not continuously raised classroom expectations, aggressively pursued continuous improvement, and fully utilized the resources of alumni and industry guidance.
\end{abstract}

This paper will describe the self-evaluation process taken by the department faculty, which resulted in the decision to break free from traditional thinking, and strive to meet the current accreditation standards of TAC/ABET.

\section{Introduction}

The B.S. in Aeronautics Degree with Concentration in Aircraft Maintenance Engineering (hereafter referred to as the AME degree) is geared toward students "interested in the theoretical aspects of aerospace engineering, but desire a practical "hands-on" career in which to put their engineering skills to use" ${ }^{3}$. 
The program is segregated into two distinctly different portions. The first four semesters are primarily dedicated to providing aircraft maintenance training. At the completion of the first half of the program, the student has satisfied the FAA requirements to be examined for and hold the Airframe and Powerplant License (hereafter referred to as an A\&P license). This license allows the holder to perform various inspections, repairs, and maintenance to aircraft and return them to service. The final four semesters require the student to complete a truncated aerospace engineering curriculum. All major topics are covered with varying levels of detail. Aeronautics and structures are emphasized and general sciences such as physics and chemistry are introduced.

In the aviation community, AME graduates can look forward to possible careers involving design of repairs and alterations, developing maintenance procedures and techniques, design of maintenance programs and technical service publications, flight test evaluation, and numerous other positions that require an understanding of aircraft maintenance skills coupled with a fundamental understanding of aerospace and structural engineering.

Currently the AME program is accredited by the Council on Aviation Accreditation (CAA). The CAA specializes in the accreditation of aviation programs. ${ }^{4}$ The types of programs accredited by the CAA include: business and management, air traffic control, professional pilot, avionics and technology programs. The CAA is a reputable accreditation organization and is held in high regard in the aviation community. However, it was the growing consensus in the Department of Aerospace Technology that the AME program may be better served by looking to an accreditation organization that specialized in engineering technology program. Over the years, the AME program had simply not been progressing and making the technical improvements that some other engineering and engineering technology programs have made.

The Department of Aerospace Technology began looking for ways to improve the AME program. Based on current enrolment and the short-term outlook it was believed that the faculty should act prior to any administrative actions that are beyond the control of the department. Our goal is to redevelop the AME program into a thriving program. The first step in developing a successful program is to define success. Additionally we considered how to maintain the program to best ensure its relevance and to avoid the pitfalls that have lead to its current state. We believe our selection of accreditation organization will be a major contributor to guarantee continuous improvement.

\section{Measuring Success}

In redefining the curriculum and thrust for the Aircraft Maintenance Engineering program, quality will play a crucial role in determining what changes will occur. Additionally those attributes of the existing program that lend themselves to excellence and merit inclusion will be synthesized within the proposed program.

The term quality in defining an academic program takes its form from a number of different perspectives. One school of thought maintains "engineering schools should broaden the 
curriculum, make engineering leadership a principle focus, and increase emphasis on manufacturing engineering and stress comprehension over computation."

While the faculty may define the virtues of the program in their own way, those attributes most valued by the programs constituency may be varied and include:

Faculty

- Faculty are qualified and experienced

- Faculty are available for advising

- Faculty are diverse

$\circ$ Faculty are current in their discipline

Graduates

○ Graduates have the ability to think critically

- Graduates are competent; employable/graduate school

- Graduates have exposure to multi-disciplines

○ Graduates are prepared for life-long learning

The Program

○ Program is accredited

- Program is relevant and timely

- Program is accessible

○ Program uses appropriate technologies

Support

○ Support - Institutional

- Support - Administrative

- Support - Faculty

○ Support - Students, Alumni and Industry

Industry $^{6}$

- Graduates are employable

○ Graduates have the ability to think critically and creatively

- Graduates have teamwork skills

○ Graduates possess communication abilities

From an operational and pragmatic perspective the program is expected to attract a sufficient number of students to allow it to be financially viable. Tuition is not expected to be the sole source of funding. Industry support and cooperation as well as a proactive faculty and administration in seeking additional revenue streams will assist in the overall economic structure and success of the program.

Another criterion as a measurement of quality in any academic program is its adherence to the organizations mission statement. The Saint Louis University mission statement mandates 
excellence in teaching and research. In its role as a Catholic, Jesuit university Saint Louis University has instituted a core curriculum that cuts across all academic departments and ensures a broad introduction to disciplines that historically have been beyond the scope of many engineering/technology programs. The core curriculum complements the attempts of engineering organizations to offer a well-rounded education to its graduates.

The current mechanism in place to evaluate programs under the auspices of the Aerospace Technology Department must be modified to assess the quality of any and all program changes. Feedback channels will be developed and promoted to provide an adequate means of measuring the strengths and weaknesses within the department.

Any reader who is familiar with TAC/ABET criteria for accrediting engineering technology programs will find much of the above very familiar. Our discussions of improving the AME and maintaining continuous improvement quickly turned to considering TAC/ABET accreditation.

\section{Considering TAC of ABET}

In the fall of 1999 the Department of Aerospace Technology acting on its own initiative formed a Program Evaluation Committee. The committee consisted of several faculty members, one of which served as chair, and the Associate Dean of Aviation for Parks College who was acting as interim department chair. The committee's primary objective was to evaluate the impact to the department of obtaining TAC/ABET accreditation. The committee's evaluation of TAC/ABET was occurring at the same time that TAC was considering sweeping changes to the criteria for accrediting engineering technology programs. These changes were identified as proposed changes and published in the last several pages of the document that specified the criteria for accrediting engineering technology programs for the evaluations during the 2000-2001 accreditation cycles. Further in the proposed changes it was stated that the new criteria (ET2K) would not be fully implemented until Fall of 2004. ${ }^{7}$ The specifics of the evaluation criteria were not of issue to the aerospace technology faculty. The greater issue was weather or not the benefits of TAC/ABET accreditation outweighed the cost. In evaluating what TAC/ABET had to offer us, we used the criteria for accreditation effective for the 2000-2001 cycle. We believe the essence of what TAC/ABET is looking for in the criteria for the 2000-2001 cycles was maintained in the proposed ET2K criteria. The department also feels that what we are looking for as benefits to TAC/ABET will be maintained in ET2K.

The question becomes "What will TAC of ABET give us that CAA doesn't?" There are several similarities. They both require proof of administration support, adequate library resources, some minimum standards of faculty and faculty development. What we were looking for was an organization that would mandate compulsory evaluation and improvement. We have learned over the years that despite the best of intentions, continuous improvement cannot be entirely selfimplemented. The TAC of ABET had two mechanisms that appear to make complacency less likely.

Proceedings of the 2001 American Society for Engineering Education Annual Conference \& Exposition Copyright (C) 2001, American Society for Engineering Education 
1) Industrial Advisory Committee is required ${ }^{7.8}$ Each program is required to have an industrial advisory committee to assist the department in items such as reviewing program content, assist in recruitment of faculty, and assist in the placement of graduates just to name a few.

2) Graduates success is measured and tracked. ${ }^{7,8}$ The program must demonstrate that employers are satisfied with the recent graduates. This data must be documented and maintained for presentation upon request by visiting teams.

The TAC of ABET also offered the advantage of being evaluated by the engineering technology community as opposed to the aviation community. We felt this would ultimately result in our students being more technically competent and better prepared for engineering positions and graduate school.

Seeking TAC/ABET accreditation was not a new idea for the department faculty. It had been considered in the past and rejected for several reasons. Most of the concern had to do with changing the name of the degree to include the word "technology". The main concerns are listed below.

1) Acceptance of graduates in aviation community. It was unclear how employers in the aviation community would compare a B.S. in Aeronautics (concentrating in Aircraft Maintenance Engineering) to a B.S. in Aircraft Maintenance Engineering Technology. Most of our graduates are eventually employed by a relatively small number of employers. It was unclear how they would respond to the change.

2) Loss of alumni support. In the past, AME alumni have provided a great deal of support to the college and the program. There was some concern that we lose their support if we effectively eliminated the program they graduated from.

3) Curriculum impact to A\&P portion of program. Over the years our alumni have told us repeatedly how much they appreciate the "hands-on" skills they developed while working toward their A\&P license. Based on the stringent curriculum requirements of TAC/ABET we were unsure that we could offer all of the instruction necessary to meet the FAA requirements for an A\&P license, and still have an eight-semester program. The department needed to know the adverse effects of limiting the A\&P instruction.

4) Alienation of current students. The department is concerned with how our current students will react to dramatic changes to the program in which they are enrolled. We do not want the students to get the impression that the degree they were working toward was somehow sub-par, thus we needed to replace it with a new one.

To address and evaluate the validity of the concerns, a timely process was developed which considered these concerns individually, then accessed the complete data at the end of the process. 
The process is outlined in Figure 1.

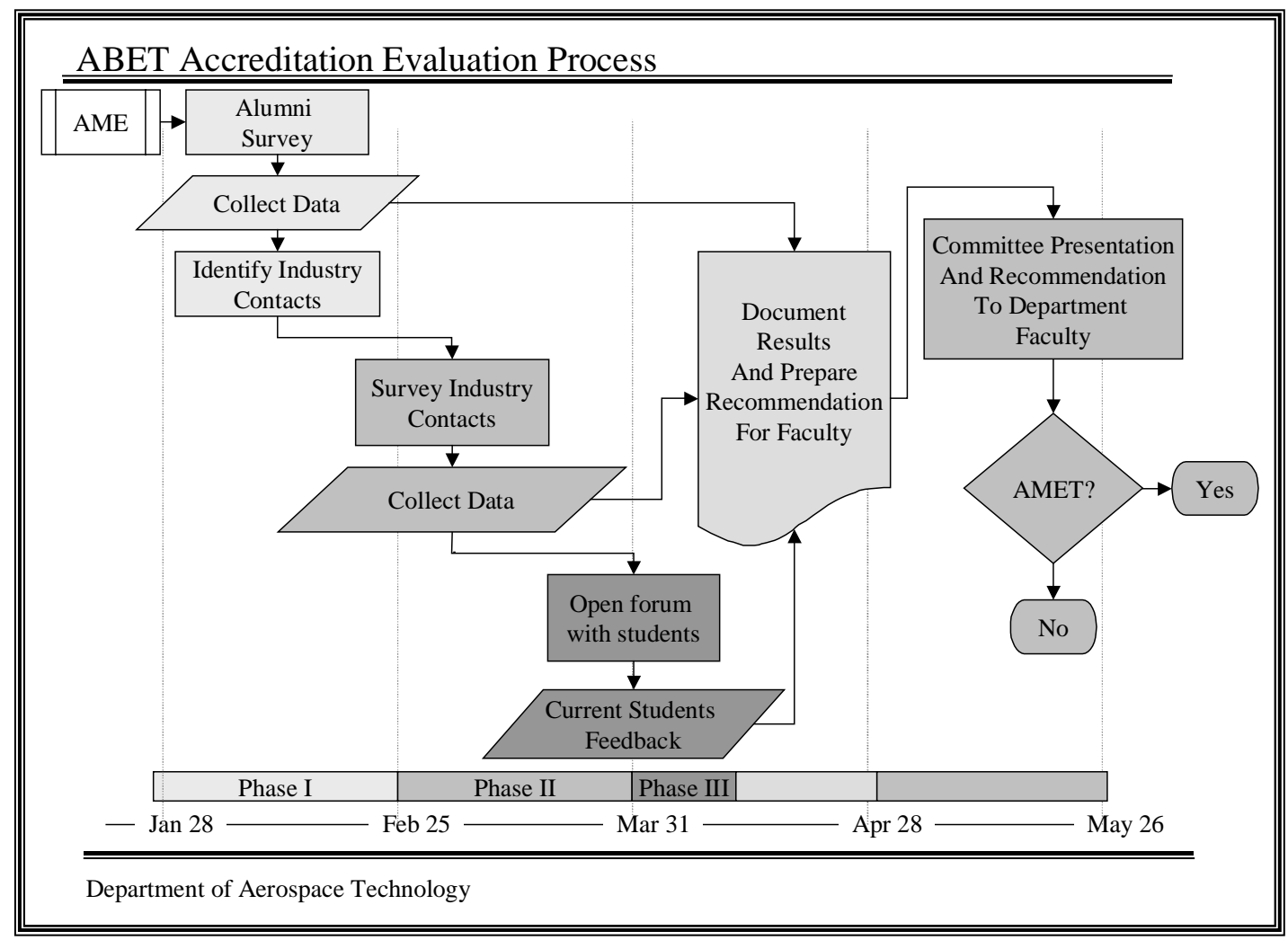

Figure 1. Evaluation Process

Phase I was a survey of the alumni. They are believed to be our greatest asset and we wanted to know how they felt about changing the program. We were also trying to find out exactly how important they felt the A\&P component of the program was, how their career progressed, and we wanted to know if they felt the ability to become professionally licensed was important to them. We believed that a TAC/ABET graduate would have fewer problems obtaining a P.E. license than someone with a non-ABET degree. We had little indication as to how much of an issue it is to engineers in the aviation community. Finally as part of the survey we were looking for contacts for Phase II of the evaluation process. We were looking for graduates in managerial positions who could help us with the industry related areas of concerns. The survey is shown in Figure 2. 


\section{SURVEY OF AIRCRAFT MAINTENANCE ENGINEERING GRADUATES}

\section{Demographic Information}

1. Male Female

2. Graduation Date:

$\begin{array}{llllll}1995-1999 & 1990-1994 & 1985-1989 & 1980-1984 & 1975-1979 & 1970-1974 \\ 1965-1969 & 1960-1964 & 1955-1959 & 1950-1954 & 1945-1949 & 1940-1944\end{array}$

1935-1939 1930-1934

\section{Professional Experience}

3. Do you hold an FAA A\&P certificate? Yes No

4. What is the highest degree you now hold? Bachelors Masters Doctorate

5. In what field is your highest degree? (check all that apply) Aeronautics (AME)
Engineering
Technology
Aviation
Business
Education

Other, please specify:

6. What was your first 'career' position after graduating from Parks College?

CompanyName Title

7. What is your current title?

Company Name Title

8. How would you best describe the minimum educational requirement for your current position? B.S. in Engineering B.S. in Engineering or Technology Bachelors Degree (any field) Other, please specify:

9. How would you best describe the educational background of your colleagues? (Degree/Major)

10. Have you ever been employed in a position that required you to hold an A\&P certificate? Yes No

11. Have you ever been employed in a position that required the skills you developed in the A\&P program, but not necessarily a valid certificate?

Yes No No Opinion

12. Are you a licensed Professional Engineer (PE)? Yes No

13. In your career thus far, would you have (or have you ) benefited by holding a
PE license?
Yes No No Opinion

14. Based on your professional experience, would graduates of the AME program benefit more from accreditation by ABET Technology (B.S. in Aircraft Maintenance Engineering Technology) or by the Council on Aviation Accreditation (B.S. in Aeronautics with a concentration in AME)? ABET(T) CAA No Opinion

Please include any additional comments on the reverse side.

Would you be willing to discuss this issue with a faculty member from the Department of Aerospace Technology? Yes No If yes, please provide your name, phone number and/or e-mail address below.

Thank you for your assistance with this survey.

Figure 2. Survey Form 
Phase II of the process was an evaluation of how the new B.S. in Aircraft Maintenance Engineering Technology (hereafter referred to as the AMET) would be viewed from the aviation industry perspective. At the end of the survey, in addition to asking for further comments we requested permission to follow up with further questions. The respondent's current position and employer were documented as part of the survey. This allowed us to review the surveys and identify alumni by industry segment (manufacturing, airline, service, etc.) and position. We were looking for a cross section of the aviation community and people in managerial and leadership positions. These individuals were then contacted via telephone or e-mail. The individuals were asked to assess how changes from AME to AMET might effect employment.

Phase III of the process was to inform the students of the possible changes to the program, and to address their concerns. It also served to dispel some of the rumors that had been circulating about the fate of the program.

The results of all three phases were then documented and presented to the Aerospace Technology Department faculty, with a recommendation from the committee.

\section{Evaluation Results}

Surveys were sent to all AME alumni. Much to our surprise over $25 \%$ of our alumni took the time to complete and return the survey. Based on past history of similar surveys, we were told to expect a response rate of $10-15 \%$. Of those who responded, over $30 \%$ provided additional comments, and many attached lengthy letters expressing their opinion. Approximately 59\% of the respondents stated they would be willing to discuss the proposed changes in greater detail with a department faculty member. Below are some of the highlights of the survey.

- Percentage of graduates who hold an A\&P license.....95\%

- Percentage of graduates ever employed in position that required either a valid A\&P or the skills developed in the A\&P training..... $83 \%$

○ Percentage of graduates who went on to earn graduate degrees..... $32 \%$

○ Graduate degrees in business...................18.7\%

○ Graduate degrees in engineering or technology.... $9.6 \%$

○ Graduate degrees in aviation related field........... $3.6 \%$

- How would you best describe the educational requirement for current position?

○ B.S. in Engineering..................28.6\%

$\circ$ B.S. in Engineering or Technology... $17.9 \%$

○ B.S. (in any field) .....................38.1\%

○ Are you a licensed professional engineers (PE)?
○ yes......3.7\%
○ no......96.3\%

- In your opinion, would your career have benefited by holding a PE license?

○ yes.....29.8\%

○ no......53.9\% 
○ Based on professional experience would graduates benefit more from degree accredited by TAC/ABET or CAA?

$\begin{array}{ll}\circ & \text { TAC/ABET ..... } \\ \circ & \text { CAA ............... } 17.7 \% \\ \circ & \text { No opinion....... }\end{array}$

The comments that were received covered the extremes of both sides. One respondent in particular stated that putting the word "technology" in the degree name would be the "kiss of death" for the program. Many of the opposing views simply stated "its about time". Between the extremes, the program evaluation committee made the following conclusions.

- The A\&P portion of the program has proven to be extremely valuable to our graduates and should continue to be offered to completion.

- Most graduates believe obtaining a PE license would not benefit their career.

- A small number of graduates would benefit.

○ Our graduates are using their degrees. Almost half are employed in positions that specifically require a degree in engineering or engineering technology. Only $15 \%$ indicated they work in a position that does not require a bachelor's degree.

$\circ$ There is not a great deal of resistance to changing the name of the program to meet TAC/ABET requirements.

Phase II of the evaluation did not yield nearly such quantitative results. We successfully identified several managers and senior engineering personal from different segments of the aviation industry who could either respond on their own or contact the appropriate human resources personnel on our behalf. Employers did not offer any firm view on differentiating between AME and AMET graduates. In general, graduates of either program could be considered for any position requiring a degree in engineering. In fact, many job posting state education requirements of "B.S. in engineering or equivalent". Thus, to many employers, on the surface the change would be transparent. To substantiate any differences in the employability of an AME graduate versus an AMET graduate you must examine what each program has to offer our students. The AME graduate has fifty years of history and distinguished alumni behind them. In an industry as close knit as aviation, name reorganization and the heritage of the program is a significant advantage. The AMET graduates will complete a more rigorous program. With a stronger curriculum that will continue to grow and improve under the auspices of TAC/ABET, ultimately AMET graduates will be better prepared for the job market. The department faculty believed the decision should be made based on the long term prospects of the program, thus the AMET option appeared to the best decision for our students.

Phase III of the evaluation consisted of providing a presentation of the proposed changes to the students and listening to their concerns. Much to our surprise, the students were more concerned with finding out what additional coursework they could do to get the AMET (if implemented) instead of the AME. 
An extremely important factor in considering TAC/ABET accreditation has not yet been discussed. That is the impact on accreditation to the department faculty. Currently only one faculty member clearly meets the TAC/ABET requirements for basic credentials. In consideration of deficient faculty credentials there are three approaches to alleviate the problem. ${ }^{9}$

1) Terminate faculty member's participation in the program.

2) Upgrade the credentials of participating faculty.

3) Hire new faculty with basic credentials.

Combinations of all three approaches were discussed, and are beyond the scope of this paper. The committee concluded that is was entirely possible to realign the department to meet the faculty requirements of TAC/ABET.

At the completion of the process the program evaluation committee presented the results to the entire Aerospace Technology Department Faculty. After discussion and debate the faculty voted unanimously to update the current AME program, make the changes necessary to meet the requirements of the TAC of $\mathrm{ABET}$ and seek $\mathrm{ABET}$ accreditation.

\section{Conclusions}

The process of change can be unwieldy and intimidating, yet in the case of the Department of Aerospace Technology the change is a first step in reestablishing vitality and strength to a once thriving program.

We are in the process of redefining the curriculum and its affect on accreditation. The A\&P portion of the program currently occupies approximately four semesters and fifty-plus credit hours. Based on the curriculum requirements of TAC/ABET it is apparent that the duration and credit weight of this portion of the program must be reduced. We are currently in the process of doing exactly that. Reducing the time and credit for the A\&P portion of the degree will allow for the inclusion of upper level engineering courses to meet the needs and requirements of the TAC of ABET.

To maintain the integrity of the program a comprehensive feedback and quality surveying instrument will be developed. Tracking the progress of our students as they move through the program and ultimately when they reach the work force will serve as a valuable measure of how the department is fulfilling its mission.

Garnering data from students and employers serves no useful purpose if it is not used to better the program. Strengths of the program should be maintained while weaknesses should be fortified.

The changes to the Aircraft Maintenance Engineering degree are intended to strengthen the degree and increase enrolment. The attributes that make the program strong today are not necessarily the 
same attributes that will make it strong tomorrow. Through careful planning, review, and adjustment the degree program will meet the needs of our students, their employers and the epistemological philosophies of a technologically driven society.

Bibliography

1. St. Louis University Bulletin, Parks College of Aeronautical Technology, v44 no3, March 48

2. St. Louis University Bulletin, Parks College of Aeronautical Technology, v45 no3, March 49

3. URL: http://imagine.slu.edu/parks/aircraft_maintenance.html; The Department of Aerospace Technology, Degrees Offered

4. URL: http://www.caaaccreditation.org/about.html-ssi; Council on Aviation Accreditation, About CAA

5. Robert P Morgan, Proctor P. Reid, and Wm. A. Wulf. The changing nature of engineering. ASEE Prism 7 no9 12$17 \mathrm{My} / \mathrm{Je}$ '98

6. George D. Peterson Engineering Criteria 2000: A Bold New Change Agent ASEE Prism v7 p30-4 September '97

7 Criteria for Accrediting Engineering Technology Programs, Effective for Evaluations During the 2000-2001 Accreditation Cycle, TAC of ABET, Baltimore MD, Proposed Engineering Technology Criteria 2000 (ET2K), p30-35

8. Criteria for Accrediting Engineering Technology Programs, Effective for Evaluations During the 2000-2001 Accreditation Cycle, TAC of ABET, Baltimore MD, p1-29

9. Wesley L. Baldwin, The Impact of Accreditation on Faculty, The Technology Interface, Spring 1999, Vol2 No2 http://bsu.edu/tti

\begin{abstract}
AARON R. COWIN
Aaron Cowin is an Assistant Professor of Aerospace Technology at Parks College of Engineering and Aviation of Saint Louis University. He teaches Machine Tools and Composite/Wood Materials. He has a B.S. in Aeronautics from St. Louis University, an M.S. in Mechanical Engineering from Washington University in St. Louis, and is working toward a PhD in Mechanical Engineering through the APOGEE Program at the University of South Carolina.

\section{TERRENCE K. KELLY}

Terrence Kelly is a Professor of Aerospace Technology at Parks College of Engineering \& Aviation of Saint Louis University. His area of expertise includes Aviation Safety, Aircraft Systems and Aerodynamics. He is a graduate of Parks College of Engineering \& Aviation of Saint Louis University with a Bachelors Degree in Aeronautics. He holds the FAA Airframe \& Powerplant Certificate, Inspection Authorization and is an FAA Designated Mechanics Examiner.
\end{abstract}

